\title{
APLICAÇÃO DA ABORDAGEM DE SERVIÇOS ECOSSISTÊMICOS NA AVALIAÇÃO DE IMPACTO AMBIENTAL DE UM ATERRO INDUSTRIAL CLASSE II
}

Lara Rúbia Borges Silva - borgesrubialara@ gmail.com Universidade Federal de Uberlândia

Maria Rita Raimundo e Almeida - mrralmeida@ ufu.br Universidade Federal de Uberlândia 

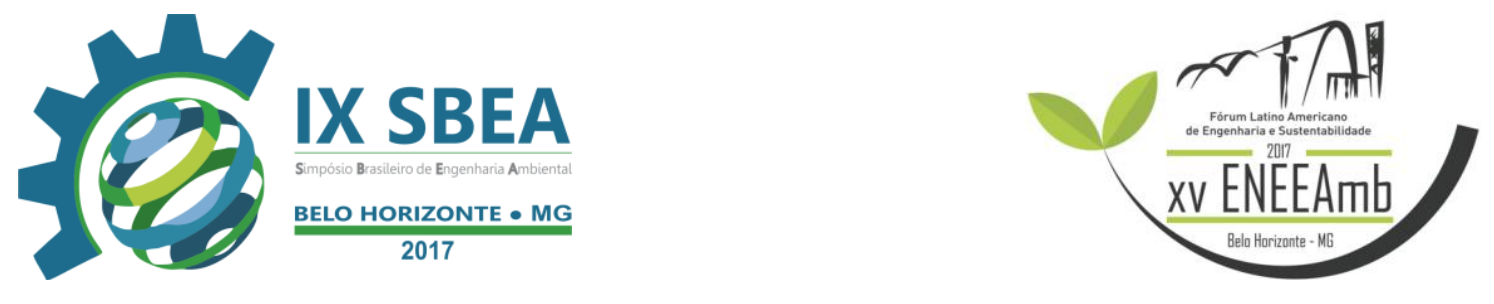

\section{RESUMO}

Serviços ecossistêmicos são processos através dos quais os ecossistemas naturais sustentam a vida humana. Este conceito pode ocasionar em uma análise integrada dos efeitos sociais e ambientais de projetos, resultando na mitigação de algumas deficiências encontradas na atual prática da Avaliação de Impacto Ambiental (AIA), sendo a AIA uma importante etapa no Licenciamento Ambiental de empreendimentos de grande potencial poluidor. Sendo assim, esta pesquisa visa verificar quais contribuições à aplicação de uma metodologia de abordagem de serviços ecossistêmicos (ASE) pode trazer à AIA, tendo como estudo de caso um projeto de Aterro Industrial na cidade de Uberlândia, Minas Gerais. A coleta de dados foi feita por análise documental do estudo de impacto ambiental (EIA) desse empreendimento e a análise dos resultados se deu por meio da comparação entre os resultados obtidos pelo teste da ASE e as etapas do processo de AIA. Os resultados apontam que uma adequada integração do conceito de serviços ecossistêmicos à prática atual de AIA pode promover uma reestruturação de algumas de suas etapas, podendo resultar em benefícios múltiplos, como uma avaliação mais ampla e efetiva dos impactos imediatos e de longo prazo de um projeto.

Palavras-chave: Serviços Ecossistêmicos, Aterro Industrial Classe II, Avaliação de Impacto Ambiental.

\section{INTRODUÇÃO/OBJETIVO}

O desenvolvimento econômico e o bem-estar humano estão intrinsicamente relacionados com a qualidade e quantidade dos serviços e fluxo de bens resultantes da atividade dos ecossistemas (PARRON, 2015). Serviços ecossistêmicos (SE) podem ser definidos, segundo MEA (2003), como benefícios que as pessoas recebem dos ecossistemas, e se dividem em quatro categorias; (1) serviços de produção (comida, água potável, combustível, fibras, compostos bioquímicos e recursos genéticos); (2) serviços de regulação (de enchentes, de secas, da degradação dos solos, e de doenças); (3) serviços de suporte (formação dos solos e os ciclos de nutrientes), e (4) serviços culturais (o recreio, valor espiritual, valor religioso e outros benefícios não materiais). 

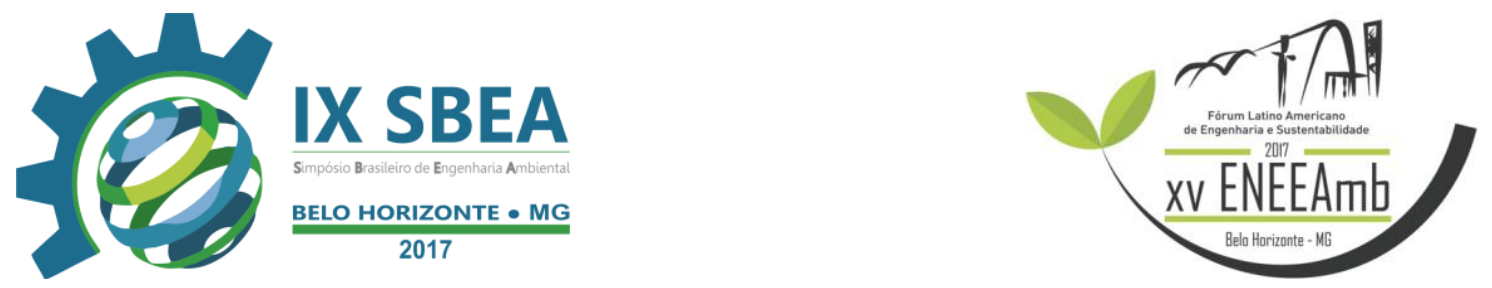

Pensando na preservação destes recursos, foram criados instrumentos de gestão como a Avaliação de Impacto Ambiental (AIA), que é o instrumento de mais utilizado no mundo para identificar os impactos possíveis que poderão ser provocados por um projeto. No entanto, a atual prática da AIA possui inúmeras deficiências como uma incompleta identificação de impactos e uma pobre avaliação de sua significância. Essas deficiências geram Estudos de Impactos Ambientais (EIA) incompletos e pouco analíticos e que não levam em consideração os serviços ecossistêmicos (ROSA, 2014).

Deu-se assim a utilização de outra abordagem para preencher as lacunas da AIA sobre os serviços ecossistêmicos chamada de Abordagem de Serviços Ecossistêmicos (ASE). Essa abordagem é uma análise conjunta dos efeitos sociais e ambientais na elaboração de projetos e na avaliação de seus impactos e pode ser obtida aplicando o conceito de serviços ecossistêmicos que contribuiria para solucionar algumas deficiências recorrentes da prática da AIA (ROSA, 2014).

Assim sendo, este projeto propõe avaliar como a aplicação de uma metodologia de abordagem de serviços ecossistêmicos favorece o aprimoramento da AIA de um Aterro Industrial - Classe II que está sendo implantado em Uberlândia, Minas Gerais.

\section{METODOLOGIA}

Com o propósito de aferir as contribuições da ASE à AIA foi selecionado um projeto de Aterro Industrial Classe II da cidade de Uberlândia, Minas Gerais. Este empreendimento, chamado de LRI-UDI-KII, possui uma área total de 17,2441 hectares e a estimativa inicial de vida útil de aproximadamente 25 anos. Este aterro industrial é classificado como Classe II, pois é destinado ao recebimento de resíduos não perigosos de origem industrial como lixo comum e resíduos orgânicos provenientes da produção industrial e pedras e resíduos de construção civil.

Os procedimentos metodológicos a serem utilizados foram baseados em Rosa (2014) que utilizou a forma de aplicação da Abordagem de Serviços Ecossistêmicos inicialmente proposta por Landsberg et al. (2013), que considera apenas os serviços de provisão, regulação e culturais. A principal diferença dos procedimentos utilizados por Rosa (2014) para aqueles aqui aplicados é que o presente projeto focará sua coleta de 


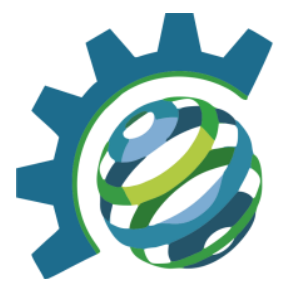

dados apenas em informações presentes EIA e não contará com visitas de campo. O desenho dos passos de desenvolvimento da pesquisa e a sua forma de execução são apresentados na Tabela 1. Ao final, foi realizada uma comparação da ASE com a prática de AIA do Brasil, considerando suas principais deficiências.

Tabela 1 - Desenho metodológico da pesquisa

\section{Passos da pesquisa}

1. Identificação dos SE da área de estudo: feita com base nas informações apresentadas no diagnóstico do EIA, utilizando as informações de cobertura vegetal e uso do solo.

2. Identificação dos SE potencialmente impactados: identificados a partir das relações de causa e efeito entre as ações do projeto e as características da região.

3. Comparação entre a ASE e AIA: comparação feita com base nos serviços ecossistêmicos potencialmente afetados com os impactos descritos no EIA do projeto.

4. Determinação dos SE potencialmente impactados prioritários: determinados a partir da potencialidade do projeto em alterar o serviço e a importância desse serviço.

5. Avaliação da significância dos impactos sobre os SE prioritários: leva em consideração a magnitude do impacto e a vulnerabilidade dos beneficiários afetados.

6. Comparação entre as significâncias dadas pelas abordagens dos SE e AIA: comparação feita entre os impactos prioritários apontados na ASE e no EIA do projeto.

7. Análise das medidas ambientais: análise de quais medidas apresentadas no EIA do projeto que também conseguem mitigar os impactos prioritários identificados pela ASE.

\section{RESULTADOS E DISCUSSÃO}

Os resultados desta pesquisa foram organizados de acordo com as etapas da ASE propostas por Landsberg et al. (2011; 2013) e Slootweg et al. (2010), principalmente.

\subsection{Identificação e caracterização dos ecossistemas afetados e seus serviços}

Foram identificados 9 tipos de cobertura vegetal e uso do solo na área, sendo que a maior parte da cobertura vegetal nativa encontra-se intensamente alterada e reduzida.

Os Sistemas Antrópicos (pastagem, áreas de infraestrutura e manutenção, represa, e áreas de capoeira) ocupam $91,56 \%$ de toda a área e o restante da área é ocupada por Mata Seca Decídua, Mata de Galeria, Mata Ciliar, Mata Ciliar Alterada e Área Hidromórfica que podem ser englobados no ecossistema Floresta. Existem também os Ecossistemas Aquáticos devido a presença de córregos e do Rio Uberabinha no entorno 


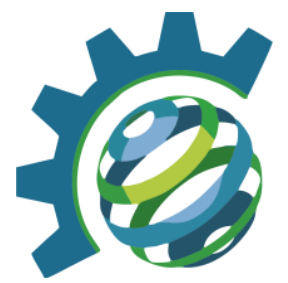

do empreendimento. Com base nestas informações, foram identificados os serviços ecossistêmicos apresentados na Tabela 2.

Tabela 2 - Ecossistemas afetados e seus serviços de acordo com informações do EIA

\begin{tabular}{|l|c|c|c|c|}
\hline \multicolumn{1}{|c|}{ Serviços } & \multicolumn{1}{c|}{ Subcategoria } & Floresta & $\begin{array}{c}\text { Sistemas } \\
\text { antrópicos }\end{array}$ & $\begin{array}{c}\text { Ecossistema } \\
\text { aquático }\end{array}$ \\
\hline Serviços de provisão & \multicolumn{1}{l|}{} & \\
\hline \multirow{2}{*}{ Alimentos } & $\begin{array}{c}\text { Culturas agrícolas e } \\
\text { criação de animais }\end{array}$ & & & \\
\cline { 2 - 5 } & \multicolumn{1}{|c|}{ Pesca } & & \\
\hline Fornecimento de água & & & \\
\hline Serviços de regulação & & & \\
\hline Regulação da qualidade do ar & & & \\
\hline Regulação do clima Regional e local & & \\
\hline Regulação da recarga hídrica e fluxos de água & & & \\
\hline Controle de erosão & & & \\
\hline Purificação de águas e tratamento de efluentes & & & \\
\hline Regulação da qualidade do solo & & & \\
\hline Serviços culturais & & & \\
\hline Valores educacionais e de inspiração & & & \\
\hline
\end{tabular}

\subsection{Identificação dos SE potencialmente impactados e seus beneficiários}

Como resultado da análise da relação de causa e efeitos foram identificados pela a ASE, os serviços ecossistêmicos potencialmente impactados, conforme apresentado na Tabela 3.

\subsection{Impactos descritos no EIA versus SE potencialmente impactados identificados pela ASE}

$\mathrm{Na}$ avaliação dos principais impactos ambientais identificados no EIA foram utilizadas e aplicadas várias classificações para cada tipo de impacto: (I) efeito causado; (II) forma de incidência no meio estudado; (III) prazo de ocorrência; (IV) abrangência; (V) potencial de recomposição do meio, indicando a reversão ou não às características originais do meio e (VI) magnitude relativa. Na fase de implantação e operação do empreendimento foram descritos no EIA os impactos principais listados a seguir que foram separados em impactos sobre os meios físico, biótico ou antrópico. 


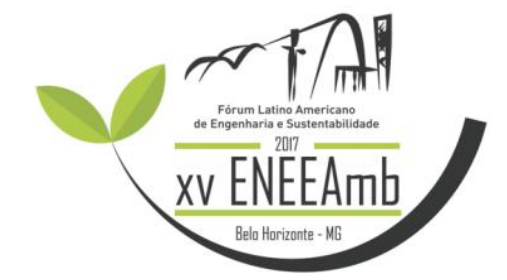

Tabela 3 - Matriz de Sistematização dos serviços ecossistêmicos potencialmente impactados por meio da análise da relação de causa e efeito

\begin{tabular}{|c|c|c|c|c|c|c|c|c|c|c|c|c|c|c|c|c|c|c|c|}
\hline \multirow[b]{2}{*}{$\begin{array}{l}\text { Forças Motoras de } \\
\text { mudança dos ecossistemas }\end{array}$} & \multirow[b]{2}{*}{$\begin{array}{l}\text { Serviços } \\
\text { Ecossistêmicos } \\
\text { Principais atividades } \\
\text { diretamente associadas } \\
\text { ao projeto }\end{array}$} & \multicolumn{10}{|c|}{ Provisão } & \multicolumn{6}{|c|}{ Reguladores } & \multicolumn{2}{|c|}{ Culturais } \\
\hline & & 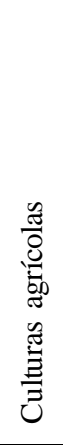 & 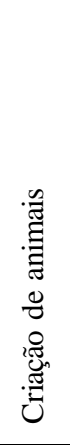 & $\begin{array}{l}\tilde{J} \\
\text { Dू } \\
2\end{array}$ & $\begin{array}{l}\frac{\pi}{3} \\
\frac{\vec{Z}}{\vec{Z}} \\
\frac{\vec{Z}}{4}\end{array}$ & 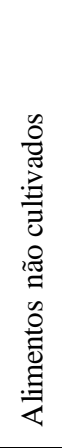 & 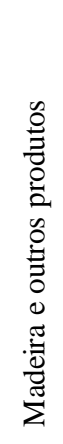 & 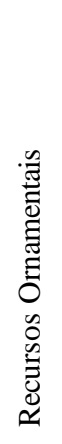 & 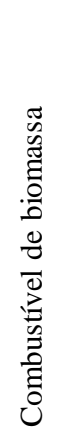 & 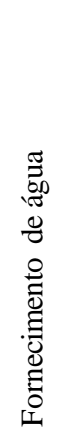 & 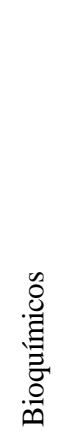 & 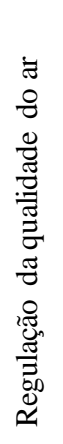 & 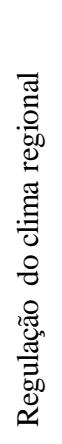 & 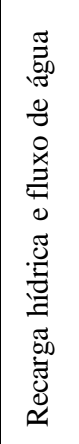 & 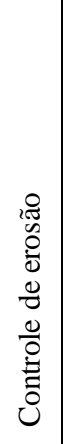 & 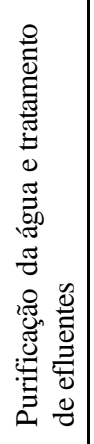 & 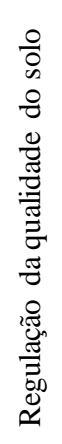 & 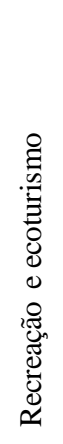 & 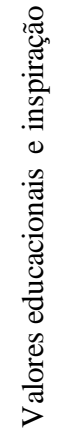 \\
\hline \multirow{4}{*}{$\begin{array}{l}\text { Mudança no uso e cobertura } \\
\text { do solo }\end{array}$} & Supressão da Vegetação & & & & & & & & & & & & & & & & & & \\
\hline & Escavação e terraplanagem & & & & & & & & & & & & & & & & & & \\
\hline & Implantação do projeto & & & & & & & & & & & & & & & & & & \\
\hline & Recuperação de Área Degradada & & & & & & & & & & & & & & & & & & \\
\hline \multirow{4}{*}{ Poluição } & $\begin{array}{l}\text { Construção e operação da área } \\
\text { industrial }\end{array}$ & & & & & & & & & & & & & & & & & & \\
\hline & $\begin{array}{l}\text { Construção e operação de } \\
\text { instalaçôes auxiliares }\end{array}$ & & & & & & & & & & & & & & & & & & \\
\hline & $\begin{array}{l}\text { Transporte de pessoas e } \\
\text { equipamentos }\end{array}$ & & & & & & & & & & & & & & & & & & \\
\hline & Manutenção & & & & & & & & & & & & & & & & & & \\
\hline $\begin{array}{c}\text { Mudanças na economia e } \\
\text { demografia }\end{array}$ & Contratação de mão de obra & & & & & & & & & & & & & & & & & & \\
\hline
\end{tabular}



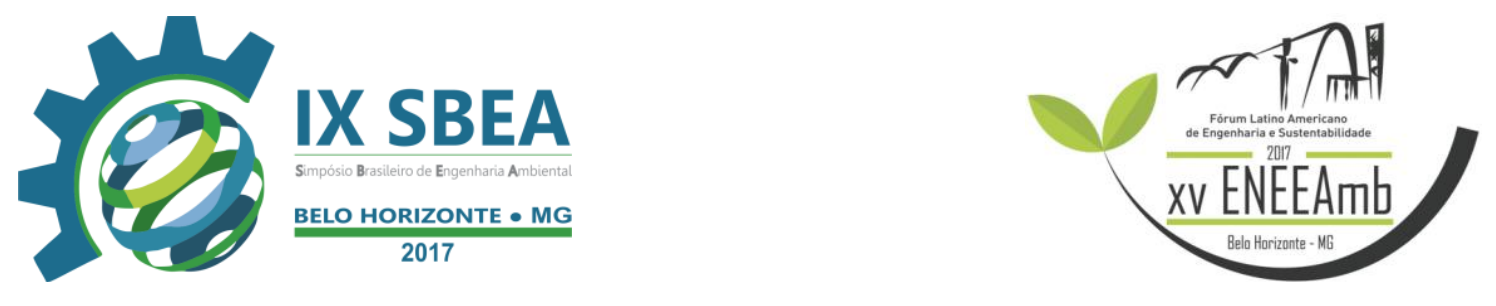

\section{Fase de Implantação do Empreendimento}

Para o meio físico: recursos hídricos: assoreamento de cursos d'água, contaminação das águas superficiais e subterrâneas; alteração do regime de recarga dos aquíferos subterrâneos com rebaixamento do nível das águas do lençol freático; solo: formação de processos erosivos em áreas de bota-fora de solo,contaminação do solo por efluentes líquidos dos veículos e equipamentos e instabilidade geotécnica de obras de corte e/ou aterro em solo natural; ar: geração e emissão de particulados (poeira). As poluições sonora e visual também poderão ocorrer, mas serão minimizadas por não haver nenhuma comunidade no entorno.

Para o meio biótico: os impactos diretos na flora serão por conta da supressão de vegetação, sendo que se concentrará na área de pastagem. Também poderá haver impactos sobre a fauna como morte e/ou afugentamento de animais e influência na nidificação das aves. Ainda, a redução da qualidade das águas superficiais causa a redução da qualidade destes habitats ou até a sua eliminação, afetando a ictiofauna.

Para o meio antrópico: efeitos na saúde devido à emissão de poeira, aumento na pressão sonora, poluição visual, aumento do tráfego de veículos pelos logradouros públicos potencializando a ocorrência de acidentes e a instabilidade social gerada junto à comunidade sobre o tipo de atividade que será desenvolvida no local.

\section{Fase de operacão do empreendimento}

Para o meio físico: recursos hídricos: além dos impactos da fase de implantação, a operação conta com impactos como a contaminação das águas por efluentes (percolados) gerados na unidade de aterragem ou por esgotos domésticos oriundos das edificações operacionais e administrativas; $\underline{\text { solo: }}$ além dos impactos da fase de implantação, a operação conta com impactos na contaminação do solo por infiltração de líquidos percolados/chorume gerados na unidade de aterragem ou por esgotos domésticos oriundos das edificações operacionais e administrativas; ar: geração e emissão de efluentes atmosféricos e particulados como poeira proveniente do tráfego contínuo de veículos, equipamentos e de interferências no solo, emanação de odores desagradáveis oriundos da biodegradação dos resíduos e gases no interior dos maciços de resíduos aterrados decorrentes da biodegradação natural dos mesmos $\left(\mathrm{CH}_{4}, \mathrm{CO}\right.$, 


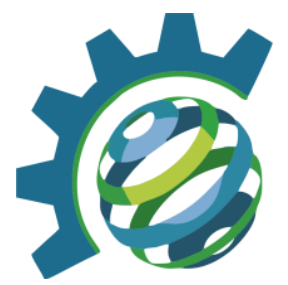

$\mathrm{CO}_{2}, \mathrm{O}_{2}$, etc). As poluições sonora e visual também poderão ocorrer devido ao funcionamento de equipamentos e veículos pesados e devido ao tratamento e disposição final de resíduos sólidos, respectivamente.

Para o meio biótico: os impactos na flora local serão por conta da retirada indevida da cobertura vegetal do terreno em áreas de empréstimo e em locais não previstos em projeto, falta de recomposição da cobertura vegetal de taludes definitivos de corte ou aterro em solo natural e contaminação da vegetação por efluentes líquidos (óleos, graxas, combustível, etc.) que porventura vazem dos veículos e equipamentos utilizados na operação do empreendimento. Em caso de falhas nos sistemas de impermeabilização e drenagem de percolados, poderá haver a alteração da qualidade do substrato onde a vegetação está estabelecida, acarretando em contaminação excessiva do solo, a eutrofização e a geração de condições anaeróbias. Também poderá ocorrer impacto sobre a fauna local que poderá ressentir pela movimentação das máquinas na época da instalação do empreendimento e das futuras atividades cotidianas do aterro, gerando um estresse adicional aos animais.

Para o meio antrópico: os impactos de cunho social que poderão ocorrer são distúrbios devido o tráfego intenso externo e interno ao empreendimento, a poluição sonora, poluição atmosférica, a contaminação dos mananciais de água, possibilidade da redução da qualidade/quantidade das águas de mananciais superficiais e geração de gases provenientes da biodegradação dos resíduos aterrados. Em relação aos profissionais responsáveis pela operação do empreendimento também poderá ocorrer impactos negativos caracterizados principalmente pela possibilidade de ocorrência de acidentes. Positivamente, ocorrerá a geração de emprego e renda para a comunidade de Uberlândia e haverá a disponibilidade de um sistema adequado de disposição final e tratamento de resíduos industriais não perigosos (resíduos Classe II) por causa do projeto.

\subsection{Serviços ecossistêmicos prioritários}

Segundo IFC (2012), uma das etapas cruciais no processo de avaliação utilizando a ASE é a priorização dos SE mais importantes da região, auxiliando no 


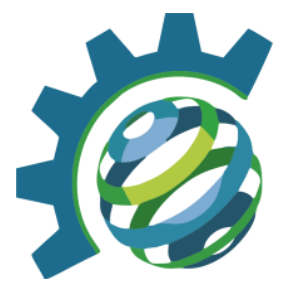

desenvolvimento do diagnóstico ambiental e na análise dos impactos. Para a realização dessa priorização, há dois critérios: (I) a potencialidade do projeto em alterar a habilidade do beneficiário em acessar o serviço e (II) a importância do serviço para o beneficiário. Segundo os critérios mencionados, foram identificados os seguintes serviços prioritários: Culturas agrícolas, Criação de Animais, Pesca, Aquicultura, Fornecimento de Água, Recarga Hídrica e fluxo de água, Purificação da água e tratamento de efluentes, Regulação da qualidade do solo, Regulação da qualidade do ar, Regulação de pragas e Polinização.

\subsection{Avaliação dos impactos sobre os serviços ecossistêmicos prioritários.}

A avaliação de impactos sobre os serviços prioritários para os beneficiários é apresentada em dois tópicos: (I) descrição dos impactos diretos e (II) avaliação da significância desses impactos. Para descrever essa etapa, foi escolhido o serviço de culturas agrícolas e criação animal como exemplo da descrição dos impactos sobre os serviços ecossistêmicos prioritários. Para esses serviços, os impactos diretos são a ocupação de pastagens e terras cultiváveis e conversão de áreas rurais e florestadas em área industrial, consequentemente aumento da erosão. A perda de produção animal e agrícola por queda da qualidade da água é um impacto indireto sobre o serviço.

4.6. Impactos significativos descritos no EIA versus impactos significativos descritos por meio da ASE.

A análise dos resultados é baseada na comparação entre a significância dos impactos do EIA, conforme descrito na metodologia. Os impactos significativos descritos no EIA se resumem em supressão de vegetação, alterações no habitat de animais silvestres, atração de animais, promoção de processos erosivos, contaminação e/ou alteração da qualidade de mananciais de água, impacto visual, ruídos, alteração no trânsito, mão-de-obra local. Segundo a ASE, foram identificados 10 impactos prioritários (item 4.5). Desses 10 impactos identificados por meio da ASE, 4 têm alguma equivalência com impactos descritos no EIA - indução de processo erosivos, 

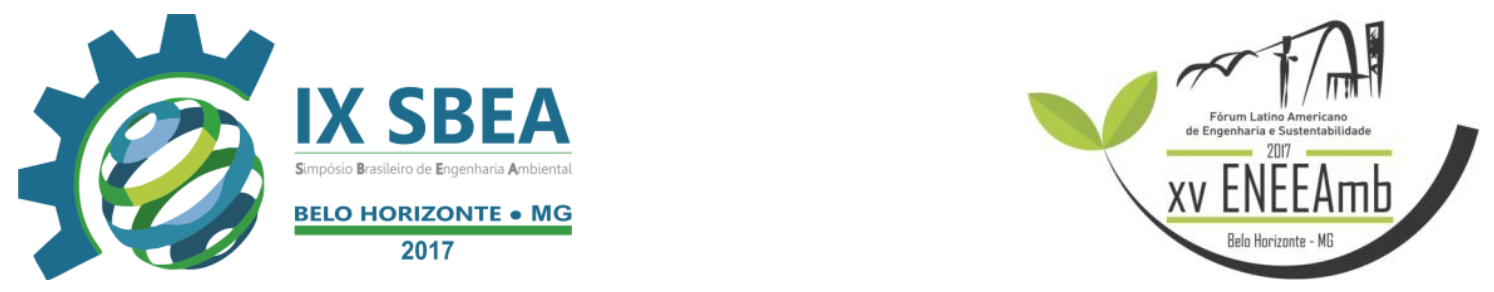

assoreamento de cursos d'água, alteração da qualidade da água e alteração da dinâmica hídrica. Os outros 6 impactos não foram descritos.

\subsection{Análise da mitigação dos impactos identificados pelo EIA e pela ASE}

No EIA foi identificado pelo menos uma medida mitigatória para cada impacto nele citado, mas nenhuma medida de compensação. Medidas de controle e minimização da poluição atmosférica serão implantadas no LRI-UDI-KII, tal como o umidecimento periódico das vias de acesso internas, o controle da qualidade e tratamento dos gases emanados pelos drenos de gases instalados nas unidades de aterragem, e o controle e manutenção dos veículos utilizados na operação do empreendimento, dentre outras. Já para o controle dos efluentes serão instalados sistemas de impermeabilização, drenagem, coleta e transporte de efluentes líquidos, viabilizando o encaminhamento de todos os efluentes líquidos gerados para o seu devido e adequado tratamento de forma a minimizar a possibilidade de ocorrência dos impactos já descritos.

Analisando as propostas de programas de mitigação nota-se que os citados no EIA agem sobre a fonte do impacto, portanto, tentam conter os processos erosivos, por exemplo, como forma de mitigar o assoreamento dos cursos d'água. Na ASE foca-se na previsão de medidas sobre os efeitos negativos sentidos pelos beneficiários, além de focar na fonte do impacto. Como por exemplo, desenvolver um plano de gestão de recursos hídricos para mitigar a alteração da dinâmica hídrica que consequentemente influencia na perda de nascentes utilizadas para abastecimento doméstico.

\section{CONCLUSÕES/RECOMENDAÇÕES}

Verificou-se que a aplicação de uma metodologia de ASE traz várias contribuições à AIA de um projeto. Assim, possui potencial para preencher algumas lacunas da AIA. Isto se deve pela amplitude de análise da ASE, abordando questões ambientais, sociais e suas relações entre si e com os beneficiários, que não são abarcados pela a atual prática da AIA. Entretanto, a ASE ainda possui limitações de vido a sua complexidade. Assim, recomenda-se mais pesquisas e estudos para resultar na padronização da classificação e numa melhor definição dos conceitos de ASE. 

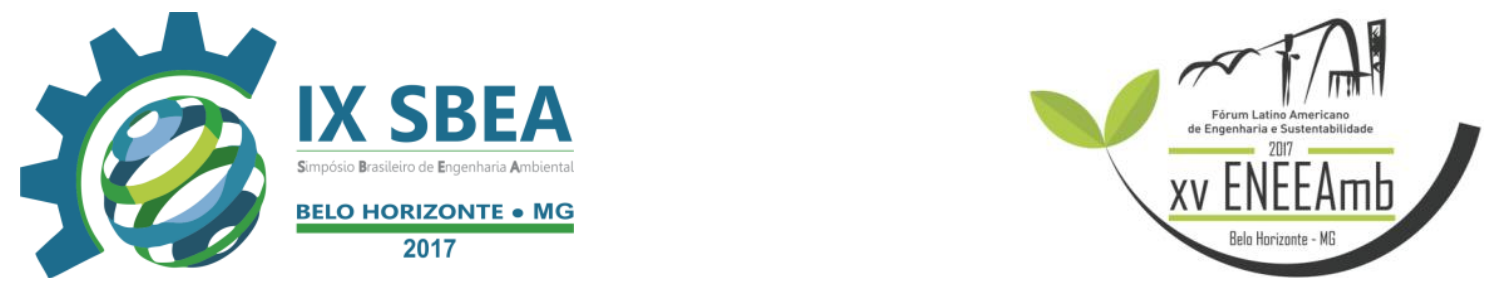

\section{REFERÊNCIAS BIBLIOGRÁFICAS}

IFC - INTERNATIONAL FINANCE CORPORATION. International Finance Corporation's Performance Standards on Environmental and Social Sustainability. Washington, DC: IFC. 2012a.

LANDSBERG, F.; OZMENT, S.; STICKLER, M.; HENNINGER, N.; TREWEEK, J.; VENN, O.; MOCK, G. Ecosystem Services Review for Impact Assessment: Introduction and Guide to Scoping. Washington: World Resources Institute, 2011. 34p.

LANDSBERG, F.; TREWEEK, J.; STICKLER, M. M.; HENNINGER, N.; VENN, O. Weaving ecosystem services into impacts assessment: A step-by-step. Washington: World Resources Institute, 2013. 46p.

MEA - MILLENNIUM ECOSYSTEM ASSESSMENT. Ecosystems and human wellbeing: a framework for assessment. Washington, DC: Island Press, 2003. 245 p. Disponível em: <http//pdf.wri.org/ecosystems_human_wellbeing.pdf>. Acesso em: 02/06/2017.

PARRON, L. M et al. Serviços ambientais em sistemas agrícolas e florestais do Bioma Mata Atlântica. Brasilia, DF. Embrapa, 2015.

ROSA, J. C. S. Avaliação de impactos ambientais de um projeto de mineração: Um teste metodológico baseado em serviços ecossistêmicos. São Paulo,180 p., 2014. Dissertação (Mestrado) - Universidade de São Paulo.

SLOOTWEG, R., RAJVANSHI, A., MATHUR, V. B., \& KOLHOFF, A. Biodiversity in Environmental Assessment: Enhancing Ecosystem Services for Human WellBeing. Cambridge University Press, 2010. 